\section{The triple airway manoeuvre for insertion of the laryngeal mask airway in paralyzed patients}

Kazuyoshi Aoyama MD, Ichiro Takenaka MD, Takeyoshi Sata MD, Akio Shigematsu MD
The efficacy of the triple airway manoeuvre (mouth opening, head extension and jaw thrust) for insertion of the laryngeal mask airway (LMA) was compared with the standard insertion method. One hundred paralyzed patients were allocated randomly into two groups: in the control group $(n=50)$ the LMA was inserted by the standard method, and in the other (TAM group, $n=50$ ) by the triple airway manoeuvre. In ten patients of each group, the position of the LMA and the epiglottis was assessed radiographically before insertion, after insertion but before cuff inflation, and after cuff inflation. In all patients the pasition was examined using fibrescopy before and afier cuff inflation. The mean distance between the epiglottis and the posterior pharyngeal wall, measured radiographically before LMA insertion, was greater in the TAM group (16.3 (SD 4.3) $\mathrm{mm}$ ) than in the control group $(7.0(2.8) \mathrm{mm})(P<0.001)$. Before cuff inflation, radiography and fibrescopy showed that the LMA compressed the epiglottis downwards more frequently in the control group. After cuff inflation the glottis was completely visible fibreoptically in $66 \%$ in the TAM group, compared with $14 \%$ in the control group $(P<0.001)$. Complete downfolding of the epiglottis was seen in $10 \%$ in the control group and none in the TAM group $(P<0.05)$. We conclude that in paralyzed patients $L M A$ insertion with the triple airway manoeuvre provides wider pharyngeal space and decreases the incidence of epiglottic downfolding by the LMA compared with the standard method.

Key words

AIRWAY: laryngeal mask;

EQUPMENT: airway, laryngeal mask.

From the Department of Anesthesiology, University of Occupational and Environmental Health, Japan, School of Medicine, Kitakyushu, Japan.

Address correspondence to: Dr. Kazuyoshi Aoyama, Department of Anesthesiology, University of Occupational and Environmental Health, Japan, School of Medicine, 1-1 Iseigaoka, Yahatanishi-Ku, Kitakyushu 807, Japan. Accepted for publication 16th July, 1995.
Cette étude compare avec la méthode dinsertion standard, l'efficacité de la triple manoeurre de libération des voies aériennes (ouverture de la bouche, extension de la tête et élévation du mandibule) pour linsertion du masque laryngé (ML). Cent patients paralysés sont répartis au hasard entre dewx groupes: dans le groupe contrôle $(n=50)$, le $M L$ est inséré suivant la méthode standard, et dans l'autre (he groupe $T M=50$ ) suivant la triple manoenvre. Chez dix patients de chaque groupe, la position du $M L$ et de l'épiglotte est évaluée par radiographie, avant linsertion, après linsertion et avant l'insufflation de la manchette, et après celle-ci. Chez tous les patients, la pasition a été vérifiée par fibroscopie avant et après linsufflation. La distance moyenne entre l'épiglotte et la paroi pharyngée pastérieure, mesurée par radiographie avant linsertion du $M L$, est plus grande dans le groupe TM (16,3 $\pm E T 4,3$ $\mathrm{mm})$ que dans le groupe contrôle $(7,0 \pm 2,8 \mathrm{~mm})(P<0,001)$. Avant linsufflation de la manchette, la radiographie et la $f-$ broscopie montrent que le $M L$ comprime l'épiglotte vers le bas plus fréquemment dans le groupe contrôle. Après linsufflation de la manchette, la glotte est visualisée dans son entier par fibroscopie chez $66 \%$ du groupe TM comparativement à $14 \%$ du groupe contrôle $(P<0,001)$. Un affaissement complet de l'épiglotte est constaté chez $10 \%$ du groupe contrôle et chez aucun patient du groupe $T M(P<0,05)$. Les auteurs concluent que pour linsertion du $M L$ chez les patients paralysés, la triple manoeuvre procure un espace pharyngé plus vaste et diminue lincidence de l'affaissement de l'épiglotte par le ML comparativement à la méthode standard.

The laryngeal mask airway (LMA) has been used for airway management during general anaesthesia in both spontaneously breathing and paralyzed patients. ${ }^{1-3}$ Insertion of the LMA is relatively easy, but the mask is sometimes misplaced. Although ventilation of the lungs is often adequate even when the LMA is misplaced, the incidence of complications is likely to be higher with an incorrectly placed mask. ${ }^{4}$ Although downward deflection (downfolding) of the epiglottis within the mask often does not compromise the airway, ${ }^{5,6}$ it may obstruct the airway in pa- 
tients breathing spontaneously. ${ }^{2,7}$ The epiglottis tends to move posteriorly in spontaneously breathing anaesthetized patients ${ }^{8}$ and upper airway structures further collapse toward one another with paralysis. ${ }^{9}$ Therefore, downfolding of the epiglottis is more likely to obstruct the airway in paralyzed patients than in spontaneously breathing patients. In addition, it is difficult to perform tracheal intubation through the LMA when the epiglottis is present in the passage. ${ }^{10,11}$ The reason for downfolding of the epiglottis by the LMA and its solution have not been well elucidated.

The triple airway manoeuvre, the combination of head extension, mouth opening and jaw thrust, is considered to be the most effective method for opening the airway. ${ }^{12,13}$ It provides a more patent airway than extension of the head without jaw thrust, ${ }^{13}$ and the latter is the head position for standard insertion of the LMA. ${ }^{14}$ We hypothesized that the LMA would press the epiglottis downwards if the pharyngeal space for the passage of the LMA were narrow compared with the thickness of the mask. Therefore, the triple airway manoeuvre may widen the pharyngeal space and decrease the incidence of downfolding of the epiglottis.

The aim of our study was to compare the efficacy of the triple airway manoeuvre with that of the standard insertion method by examining the distance between the epiglottis and the posterior pharyngeal wall and the incidence of downfolding of the epiglottis in paralyzed patients.

\section{Methods}

\section{The thickness of the LMA (in vitro)}

Two anaesthetists independently measured the thickness (antero-posterior dimension) of the LMA at the junction of the mask and the shaft, the thickest portion. The cuff was fully deflated during measurement. The thickness of five size-3 and five size-4 LMAs were measured twice.

\section{Clinical study}

We studied 100 adult patients, ASA physical status 1 or 2, undergoing general anaesthesia for elective surgery on the extremities. Institutional ethics committee approval and informed consent from each patient were obtained. Patients with oropharyngeal pathology, or morbid obesity and those at risk of regurgitation were excluded.

All patients received $0.25 \mathrm{mg}$ triazolam po two hours before induction of anaesthesia. In the operating room, the patients were monitored with an ECG, indirect blood pressure, pulse oximetry and capnogram. A firm pad $(8 \mathrm{~cm}$ in height) was placed under the patient's occiput. After preoxygenation for a few minutes, anaesthesia was induced with 3-5 $\mathrm{mg} \cdot \mathrm{kg}^{-1}$ thiopentone, $1-2 \mu \mathrm{g} \cdot \mathrm{kg}^{-1}$ fentanyl, and neuromuscular blockade was produced with $0.1 \mathrm{mg} \cdot \mathrm{kg}^{-1}$ vecuronium. The patient's lungs were ventilated with isoflurane $1-2 \%$ in oxygen via a face mask for five minutes.

The patients were randomized sequentially to one of two groups. In 50 patients the LMA was inserted by the standard method (control group), whereas in the remaining 50 patients the LMA was inserted using the triple airway manoeuvre (TAM group). After paralysis was confirmed using a nerve stimulator, the patient's head and neck were positioned for insertion of the LMA. In the control group, the patient's head was extended, the lower neck flexed (sniffing position) and the mouth opened. While in the TAM group, an assistant opened the mouth and thrust the jaw using both hands, after the operator placed the patient's head and neck in the sniffing position.

\section{Radiological assessment before insertion of the LMA}

In the first ten patients in each group, a radiograph was taken for a lateral view of the neck after positioning for insertion, before insertion of the LMA. Radiographs were obtained using a mobile $x$-ray apparatus (Toshiba, Tokyo) at $62-65 \mathrm{kV}$ and $12-15 \mathrm{mAs}$, depending on patient build, and with $100 \mathrm{~cm}$ focal film distance.

\section{Insertion of the $L M A$}

The appropriately sized LMA was selected according to the manufacturer's instruction manual. ${ }^{14}$ In the control group, the LMA was inserted using the standard method described in the manual. ${ }^{14}$ Briefly, the LMA, adequately deflated and lubricated, was firmly applied against the hard palate and advanced into the hypopharynx with the index finger. In the TAM group, the LMA was also inserted by the standard method, except an assistant applied the triple airway manoeuvre during insertion. Only one attempt at insertion was allowed.

\section{Position of the LMA before inflation of the cuff}

The position of the LMA relative to the epiglottis was assessed using a fibreoptic bronchoscope before inflation of the cuff. The fibrescope was passed through the shaft of the LMA and placed $1 \mathrm{~cm}$ proximal to the mask aperture bars. The position was scored by a blinded observer as shown in Table I. In the patients in whom the radiograph had been obtained, another radiograph was taken after insertion but before inflation of the cuff.

\section{Position of the LMA after inflation of the cuff}

After assessment of the position of the LMA, the cuff of a \#3 or \#4 LMA was inflated with 20 and $30 \mathrm{ml}$ air, respectively. The patient's lungs were ventilated man- 
TABLE I Score of the fibreoptic view of the larynx

\begin{tabular}{ll}
\hline Scone & View of the larynx \\
\hline 1 & Glottis completely visible while the epiglottis was not identified \\
2 & Glottis slightly obscured by the tip of the epiglottis \\
3 & More than half of the glottis obscured by the epiglottis \\
4 & $\begin{array}{c}\text { Glottis completely obscured by the epiglottis (complete } \\
\text { downfolding) }\end{array}$ \\
5 & Ventilation not adequate \\
A & Mask aperture adjacent to the aryepiglotic folds or the \\
& arytenoid cartilages
\end{tabular}

ually and adequacy of ventilation was assessed using a Wright respirometer and an airway pressure monitor. Ventilation was judged as adequate when expiratory tidal volume of $>10 \mathrm{ml} \cdot \mathrm{kg}^{-1}$ could be obtained at peak airway pressure of $<2 \mathrm{kPa}$. The position of the LMA was assessed again using fibrescopy (Table I). If ventilation was not adequate, the position was scored as 5 regardless of the position of the LMA (Table I). In the patients in whom the radiographs had been obtained, the third radiograph was taken after inflation of the cuff.

\section{Safety management}

If arterial haemoglobin oxygen saturation $\left(\mathrm{SpO}_{2}\right)$ decreased to $<95 \%$, the procedure was abandoned, appropriate treatment was given and the patient was excluded from the study.

\section{Data and statistical analysis}

The mean thickness of the mask measured in vitro by two anaesthetists was calculated. A single anaesthetist, who had no knowledge of the insertion method, examined the radiographs. The distance between the tip of the epiglottis and the posterior pharyngeal wall before insertion of the LMA was measured and corrected for magnification, and the distance in the two groups was compared. The distance in each group was also compared with the thickness of the mask measured.

Chi-square test or Fisher's exact test was used to compare the incidence of downfolding of the epiglottis between the two groups. Wilcoxon signed-rank test and Mann-Whitney U test were used to compare the degree of downfolding of the epiglottis before and after inflation of the cuff in each group and that between the two groups, respectively. Spearman's correlation coefficient by ranks was used to test a correlation between the epiglottisposterior pharyngeal wall distance and the degree of downfolding of the epiglottis. $P<0.05$ was considered as significant.

\section{Results}

The thickness of the LMA (in vitro)

The mean thicknesses of the masks at the widest part were 23.0 (SD 0.3) $\mathrm{mm}$ and $24.0(0.7) \mathrm{mm}$ for size 3 and 4 , respectively.

\section{Clinical study}

Patient's age, height, weight, sex distribution and the proportion of the mask size used were similar between the two groups (Table II). The $\mathrm{SpO}_{2}$ did not decrease to $<95 \%$ or the $\mathrm{PETCO}_{2}$ increase to $>50 \mathrm{mmHg}$ in any patient. The LMA was successfully inserted at the first attempt, and manual ventilation could be performed adequately in all patients.

\section{Radiological findings}

Patients' characteristics were similar between the two groups (Table II). The mean distance between the epiglottis and the posterior pharyngeal wall before insertion of the LMA was 7.0 (SD 2.8) (range: $2.5-13.1$ ) $\mathrm{mm}$ in the control group and 16.3 (4.3) (range: $9.1-25.2) \mathrm{mm}$ in the TAM group $(P<0.001$, Figure 1A, 1B). In only one patient in the TAM group was the distance greater than the thickness of the LMA.

Radiographs taken after insertion of the LMA but before inflation of the cuff revealed that the LMA compressed the epiglottis against the laryngeal inlet in nine of ten patients $(90 \%)$ in the control group and in four of ten patients $(40 \%)$ in the TAM group $(P<0.05$, Figure 2A). After inflation of the cuff, the LMA moved outward and the epiglottis was elevated by the inflated cuff (Figure 2B). The epiglottis, however, remained downfolded in these patients. The epiglottis seemed to be positioned outside the cuff in the remaining six patients $(60 \%)$ in the TAM group, but in only one (10\%) patient in the control group $(P<0.05)$.

\section{Fibreoptic findings}

Fibrescopy showed that before inflation of the cuff, the view of the glottis was completely obstructed by the epiglottis (Score 4) in 41 patients (82\%) in the control group and in 14 patients $(28 \%)$ in the TAM group $(P<0.001$, Figures 3 and 4). In some patients, the LMA was deeply advanced to lie adjacent to the arytenoid cartilages or aryepiglottic folds (Score $\mathrm{A}$ ).

After inflation of the cuff, the view of the glottis improved in most patients in both groups $(P<0.001$, Figures 3 and 4). The glottis was completely visible (Score 1) in 33 patients $(66 \%)$ in the TAM group, compared with seven patients $(14 \%)$ in the control group $(P<$ 0.001 ). The epiglottis was completely downfolded (Score 4) in five (10\%) patients in the control group but in no 
TABLE II Demographic characteristics

\begin{tabular}{|c|c|c|c|c|c|c|}
\hline & $\begin{array}{l}\text { No. of } \\
\text { patients }\end{array}$ & $\begin{array}{l}\text { Age } \\
(y r)\end{array}$ & $\begin{array}{l}\text { Height } \\
\text { (cm) }\end{array}$ & $\begin{array}{l}\text { Weight } \\
(\mathrm{kg})\end{array}$ & $\begin{array}{l}\operatorname{Sex} \\
(M / F)\end{array}$ & $\begin{array}{l}\text { Mask size } \\
(\$ 3 / \# 4)\end{array}$ \\
\hline Control group & 50 & $56.0(16.3)$ & $158.4(9.6)$ & $56.3(10.6)$ & $27 / 23$ & $24 / 26$ \\
\hline radiological study & 10 & $56.3(18.5)$ & $156.2(12.2)$ & $52.1(10.4)$ & $4 / 6$ & $6 / 4$ \\
\hline TAM group & 50 & $51.2(19.6)$ & $160.3(10.9)$ & $57.7(9.9)$ & $30 / 20$ & $21 / 29$ \\
\hline radiological study & 10 & $54.5(18.6)$ & $157.6(9.4)$ & $54.9(10.0)$ & $5 / 5$ & $6 / 4$ \\
\hline
\end{tabular}

Values are expressed as mean (SD).
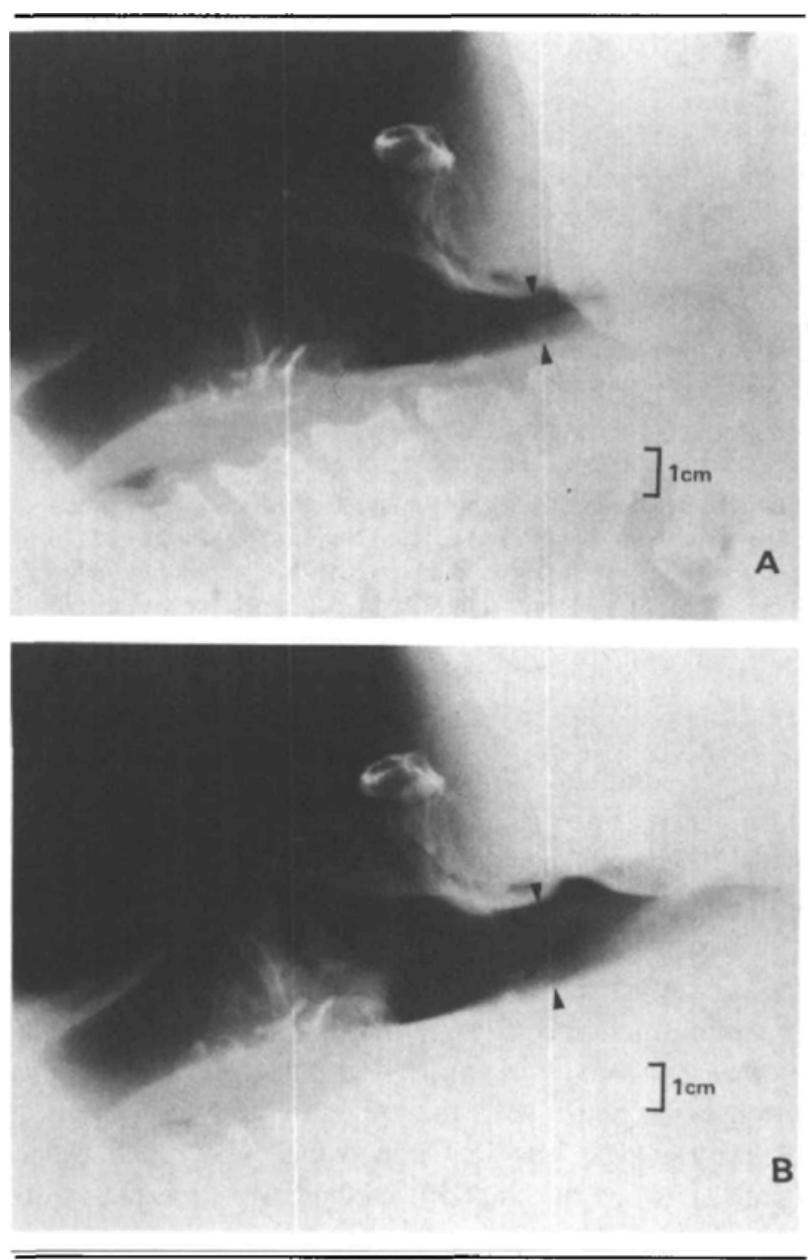

FIGURE 1 Neck lateral radiographs before insertion of the LMA showing the distance between the epiglottis and the posterior pharyngeal wall (arrows). The radiographs were obtained after positioning for insertion of the LMA. (A) The neck is flexed, the head extended and the mouth opened in a control patient (B) Triple airway manoeuvre including mouth opening, head extenșion and jaw thrust in a TAM group patient. The distance was shorter than the thickness of the mask in most patients. The mean distance in the TAM group (16.3 (SD 4.3) $\mathrm{mm}$ ) was greater than that in the control group $(7.0(2.8) \mathrm{mm}$ ) $(P<0.001)$.

patients in the TAM group $(P<0.05)$. After inflation of the cuff, the score of the LMA position in the TAM
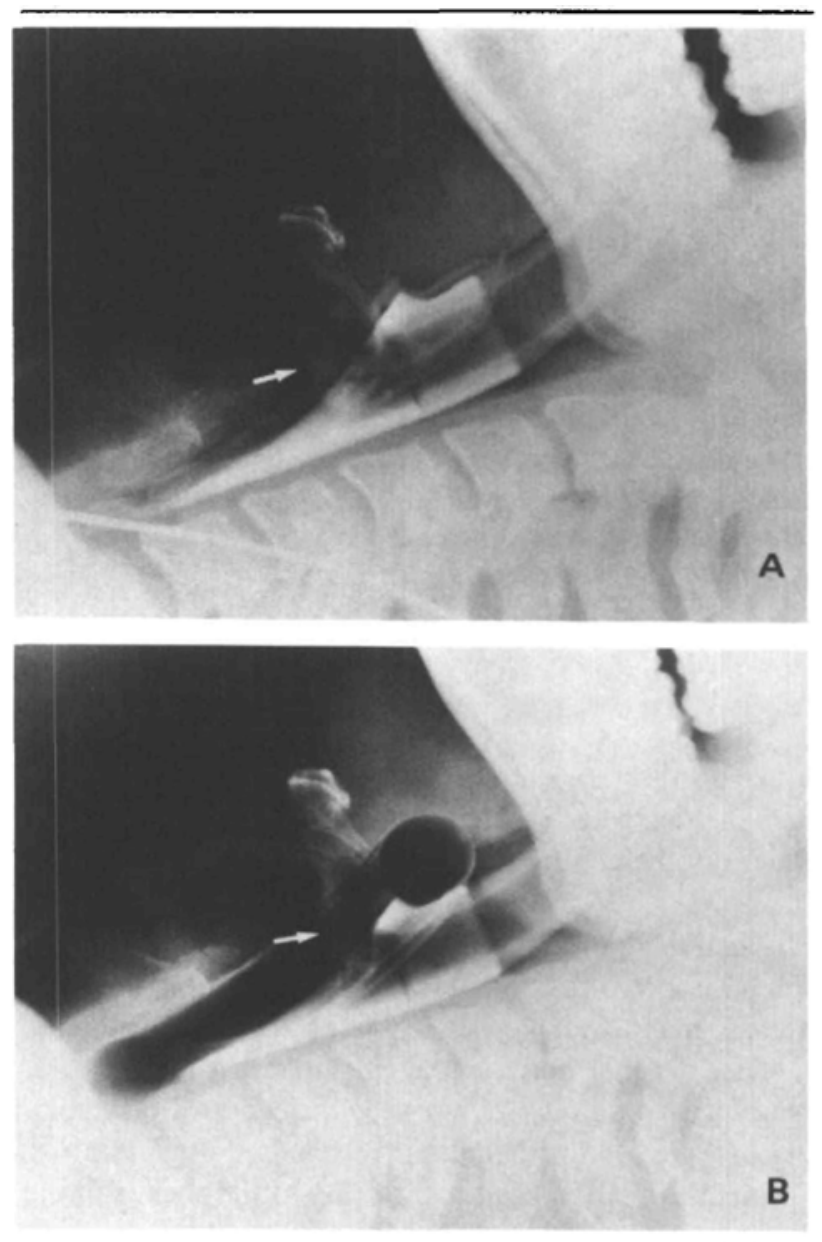

FIGURE 2 Neck lateral radiographs showing compression of the epiglottis by the mask and elevation of the epiglottis by inflation of the cuff. (A) The LMA before cuff inflation compresses the epiglottis against the laryngeal inlet, causing downwand deflection of the epiglotis (white arrow). (B) The inflated cuff elevates both the epiglottis (white arrow) and the base of the tongue. The characteristic deflection of the epiglottis is noted, although only the epiglottis tip was sen fibreoptically through the LMA (Score 2).

group was lower than that in the control group ( $P<$ 0.001 , Mann-Whitney $U$ test).

In patients who had radiographs, in both groups, there was a correlation between the epiglottis-posterior pharyn- 


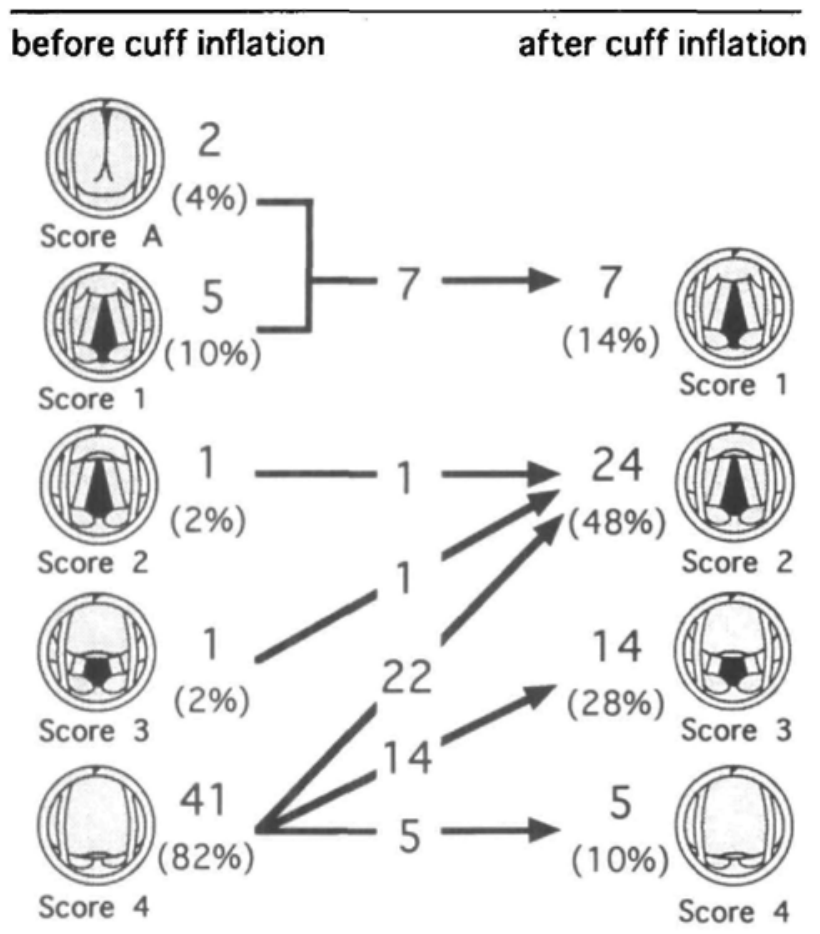

FIGURE 3 View of the larynx through the LMA before and after inflation of the cuff in the control group. Numbers of patients and percentages in parentheses are presented. before cuff inflation after cuff inflation

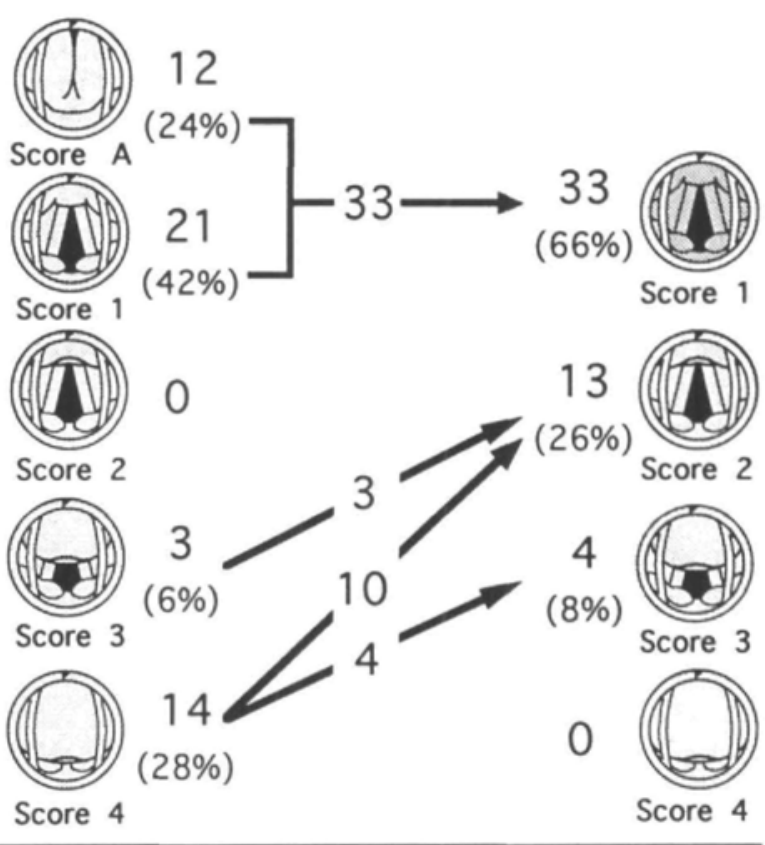

FIGURE 4 View of the larynx through the LMA before and after inflation of the cuff in the TAM group. Numbers of patients and percentages in parentheses are presented. After inflation of the cuff, the score of the LMA position in the TAM group was lower than that in the control group $(P<0.001$, Mann-Whitney $U$ test).

with the standard method often presses the epiglottis downwards, since the epiglottis is downfolded in most patients when the position of the mask is examined before inflation of the cuff.

The triple airway manoeuvre has been shown to open the airway at the oropharynx in anaesthetized patients breathing spontaneously. ${ }^{12,13}$ In our study, when the triple airway manoeuvre was applied in paralyzed patients, the mean distance between the epiglottis and the posterior pharyngeal wall was $16.3 \mathrm{~mm}$, which was much wider than that when the standard method was used $(7.0 \mathrm{~mm}$, $P<0.001$ ). The mask is thus less likely to impact upon the epiglottis during insertion. In fact, the incidence of complete downfolding of the epiglottis (Score 4) before inflation of the cuff was only $28 \%$ in patients in the TAM group, compared with $82 \%$ of patients in the control group. After inflation of the cuff, the incidence of downfolding of the epiglottis (Score 2, 3,4) in the TAM group was lower than that in the control group. In addition, there was a correlation between the epiglottis-posterior pharyngeal wall distance and the degree of downfolding of the epiglottis after inflation of the cuff. These results are consistent with the theory that the triple airway manoeuvre widens the space for passage of the LMA and 
reduces the incidence of downfolding of the epiglottis. This concurs with a proposal that a jaw thrust is useful in the insertion of the LMA. ${ }^{16}$

Despite the insufficient distance between the epiglottis and the posterior pharyngeal wall in most patients of both groups, there were several patients in whom the LMA passed without compressing the epiglottis. The reason is unclear. It may be that the mask pressed the epiglottis downwards during insertion, but the epiglottis "bucked up" to the initial position due to its elasticity. Individual variation in the size and the elasticity of the epiglottis, and in the size of the hypopharynx, as well as the space for the passage of the LMA, might have affected the location of the epiglottis.

By inflating the cuff, the degree of downfolding of the epiglottis usually decreased, and the view of the glottis improved. The incidence of complete downfolding (Score 4) decreased from $82 \%$ to $10 \%$ in the control group, and from $28 \%$ to $0 \%$ in the TAM group. These findings indicate that inflation of the cuff provides not only a seal around the larynx but an open airway. One possible explanation for the improvement of the view of the glottis by inflation of the cuff is due to elevation of the epiglottis. The radiograph obtained after inflation of the cuff showed that the cuff elevated the epiglottis. Another possible reason is because of the outwards movement of the LMA during inflation. When the cuff was inflated, the LMA usually moved out of the mouth slightly (mean distance of $0.7 \mathrm{~cm}^{17}$ ). Thus the pressure on the downfolded epiglottis by the mask was decreased, and the degree of downfolding of the epiglottis became less.

In some patients, before inflation of the cuff, the LMA was positioned too deeply, and the mask aperture was located adjacent to the aryepiglottic folds or the arytenoid cartilages (Score A). We believe that this was not due to selection of too small LMAs, as we selected the size according to the manufacturer's instructional manual. The incidence of this position was higher in the TAM group than in the control group, perhaps because of the larger space for the passage produced by the triple airway manoeuvre. In addition, the LMA may be advanced more readily to a greater depth in the paralyzed patient. Payne showed that, in spontaneously breathing patients, infolding of the aryepiglottic folds caused partial airway obstruction. ${ }^{7}$ However, in all score A patients, the LMA moved outwand by inflation of the cuff and was ideally positioned itself (Score 1).

When the LMA was inserted with the standard method, the epiglottis was completely downfolded in $10 \%$ of patients, and the epiglottis was seen in the bowl of the mask in $86 \%$ of the patients. The incidence is similar to that reported by Fullekrug et al.,$^{18}$ but is higher than that in the study reported by Asai et al..$^{19}$ and Brima- combe et al..$^{20}$ The reason for the discrepancy between our results and theirs is unclear. One possibility is that the patients' build affected the position of the LMA, since the patient's mean weight in their studies $\left(70 \mathrm{~kg},{ }^{19} 73\right.$ $\mathrm{kg}^{20}$ ) was greater than that in our study $(56.3 \mathrm{~kg})$. In relatively large patients, there may be a wider space for the passage of the LMA at the level of the epiglottis. Another possible reason is that positioning of the fibrescope also affected the view of the epiglottis. We positioned the fibrescope at $1 \mathrm{~cm}$ above the mask aperture bars whereas both Asai et al. and Brimacombe et al. placed it at the level of the aperture bars. ${ }^{19,20}$ When the tip of the fibrescope is positioned at the level of the bars, the tip of the epiglottis might have been out of view.

In our study, ventilation through the LMA was always adequate in both groups, as it has been recognized that ventilation is often adequate even when the LMA is not in the optimal position. ${ }^{5,6}$ An LMA placed in the suboptimal position, however, is likely to cause complications, ${ }^{4}$ and thus the incidence of misplacement should be reduced. We believe that, compared with the standard method, the triple airway manoeuvre facilitates optimal position of the LMA in paralyzed patients. It is, however, not known whether the triple airway manoeuvre is better than the standard method in patients breathing spontaneously. The triple airway manoeuvre may be less effective in patients who are not paralyzed, since jaw thrust may be less easy. The triple airway manoeuvre may be useful in patients breathing spontaneously when there is difficulty in placing the LMA correctly by the standard method.

To perform the triple airway manoeuvre, additional jaw thrust to the standard method is necessary. We suggest that an assistant open the mouth and thrust the jaw, the operator can then insert the LMA with the patient's head extended and the occiput stabilized properly with the non-dominant hand.

In summary, we have shown that, in paralyzed patients, insertion of the LMA by the standard method frequently compresses the epiglottis against the laryngeal inlet because of the insufficient space for the passage. The triple airway manoeuvre increases the distance between the epiglottis and the posterior pharyngeal wall, and decreases the incidence of downfolding of the epiglottis.

\section{Acknowledgments}

We thank Dr. T. Asai, Department of Anaesthesiology, Kansai Medical University and University of Wales College Medicine for his helpful comments in preparing the manuscript.

\section{References \\ 1 Brain AIJ, McGhee TD, McAteer EJ, Thomas A, Abu- Saad MAW, Bushman JA. The laryngeal mask airway.}


Development and preliminary trials of a new type of airway. Anaesthesia 1985; 40: 356-61.

2 Brodrick PM, Webster NR, Nunn JF. The laryngeal mask airway. A study of 100 patients during spontaneous breathing. Anaesthesia 1989; 44: 238-41.

3 Maltby JR, Loken RG, Watson NC. The laryngeal mask airway: clinical appraisal in 250 patients. Can J Anaesth 1990; 37: 509-13.

4 Asai $T$, Morris $S$. The laryngeal mask airway: its features, effects and role. Can J Anaesth 1994; 41: 930-60.

5 Nandi PR, Nunn JF, Charlesworth CH, Taylor SJ. Radiological study of the laryngeal mask. Eur J Anaesthesiol Suppl 1991; 4: 33-9.

6 Goudsouzian NG, Denman W, Cleveland R, Shorten G. Radiologic localization of the laryngeal mask airway in children. Anesthesiology 1992; 77: 1085-9.

7 Payne J. The use of the fibreoptic laryngoscope to confirm the position of the laryngeal mask (Letter). Anaesthesia 1989; 44: 865 .

8 Boidin MP. Airway patency in the unconscious patient. $\mathrm{Br}$ J Anaesth 1985; 57: 306-10.

9 Benumof JL. Management of the difficult adult airway. With special emphasis on awake tracheal intubation. Anesthesiology 1991; 75: 1087-110.

10 Pennant $J H$, White $P F$. The laryngeal mask airway. Its uses in anesthesiology. Anesthesiology 1993; 79: 144-63.

11 Benumof $J L$. Use of the larygeal mask airway to facilitate fiberscope-aided tracheal intubation (Letter). Anesth Analg 1992; 74: 313-5.

12 Safar P, Bircher NG. Candiopulmonary Cerebral Resuscitation, 3rd ed. London: W.B. Saunders, 1988.

13 Safer $P$, Escarraga $L A$, Chang $F$. Upper airway obstruction in the unconscious patient. J Appl Physiol 1959; 14: $760-4$.

14 Brain $A I J$. The Intavent Laryngeal Mask Instruction Manual, 2nd ed. England: Intavent, 1993.

15 Brain AIJ. Laryngeal mask misplacement - causes, consequences and solutions (Letter). Anaesthesia 1992; 47: 531-2.

16 Cass $L$. Inserting the laryngeal mask (Letter). Anaesth Intensive Care 1991; 19: 615.

17 Asai T, Latto IP, Vaughan RS. The distance between the grille of the laryngeal mask airway and the vocal cords. Is conventional intubation through the laryngeal mask safe? Anaesthesia 1993; 48: 667-9.

18 Füllekrug B, Pothmann W, Werner C, Schulte am Esch J. The laryngeal mask airway: anesthetic gas leakage and fiberoptic control of positioning. J Clin Anesth 1993; 5: 357-63.

19 Asai T, Barclay K, Power I, Vaughan RS. Cricoid pressure impedes placement of the laryngeal mask airway and subsequent tracheal intubation through the mask. Br J Anaesth 1994; 72: 47-51.
20 Brimacombe J, Berry A. Laryngeal mask airway insertion. A comparison of the standard versus neutral position in normal patients with a view to its use in cervical spine instability. Anaesthesia 1993; 48: 670-1. 